\title{
SEM SAÍDA: O INFINITO DA ESCRITA EM QUATRO-OLHOS, DE RENATO POMPEU, E “A BUSCA DE AVERRóis”, DE JORGE LUIS BORGES
}

Tiago Lanna Pissolati

Mestre em Estudos Literários do Programa de Pós-graduação em Estudos Literários / UFMG

\begin{abstract}
RESUMO
A proposta deste artigo é analisar as formas pelas quais o infinito surge no texto do romance Quatro-olhos, de Renato Pompeu, e toma as rédeas da escrita. Para tanto, realizaremos uma leitura em paralelo do conto "A busca de Averróis”, de Jorge Luis Borges, guiados pelo pensamento de Maurice Blanchot.
\end{abstract}

\section{PalaVRas-CHAVE}

Perda, escritas da ausência, escrita infinita

(...) y seguimos perdidos en el tiempo, ese otro laberinto.

Jorge Luis Borges. "El laberinto”

A escrita em busca dela mesma: essa parece ser a premissa do romance Quatro-olhos, de Renato Pompeu. Escrita durante o mais rígido período da ditadura militar brasileira e publicada em 1976, essa narrativa, ainda pouco conhecida entre a crítica literária e o público leitor, ergue-se em torno de uma ausência - um livro que o protagonista escrevera ao longo de grande parte de sua vida, desaparecido em circunstâncias, a princípio, imprecisas.

De fato, trata-se de um texto fundado por imprecisões. Escrito ao longo de mais de uma década, esse livro perdido é objeto de esquecimento do protagonista, como nos revelam as primeiras sentenças do romance:

Mais ou menos dos 16 aos 29 anos passei no mínimo três a quatro horas todos os dias, com exceção de um ou outro sábado e de certa segunda-feira, escrevendo não me lembro bem se um romance ou um livro de crônicas. Recordo, com perfeição, porém, tratar-se de obra admirável, a pôr a nu de modo confortavelmente melancólico a condição humana universal e eterna, 
particularizada com emoção discreta nas dimensões nacionais e de momento. Dei para um amigo meu, funileiro, ler e ele achou muito bom.

Perdi os originais há muitos anos, em circunstâncias que não me convém deixar esclarecidas. Do trabalho, tão importante, guardo apenas memória vaga; de que havia, indubitavelmente, um tema, ou vários temas, e mesmo um ou outro personagem, mas não consigo reproduzir um único gesto, nenhuma situação ou frase. Às vezes, sinto dúvidas e hesitações; durante algumas horas da madrugada à manhã do último Primeiro de Maio, por exemplo, cheguei a excogitar, com pânico crescente - de que não se tratava de obra-prima. ${ }^{1}$

Segue-se a esse trecho uma prosa que ora encontra seus referentes nas memórias do narrador, ora tartamudeia, afetada pelo esquecimento. É nessa prosa que se ergue a busca do protagonista por seu livro perdido ou por qualquer lembrança dele. Misturam-se, assim, lembranças de sua juventude, divagações sobre a natureza da literatura e mesmo possíveis trechos desses misteriosos originais, em um texto que parece perder-se em uma escrita sem tempo e lugar.

Há, no entanto, uma linha narrativa. Após a leitura das três partes que compõem o romance, é possível dar forma aos fatos narrados. Um homem, casado com uma militante revolucionária, tem seu apartamento invadido pela polícia política, que estava em busca de sua mulher. Não a tendo encontrado, a polícia leva os originais desse livro, escrito disciplinadamente por mais de uma década. Após esse evento, o protagonista é internado em uma instituição psiquiátrica e passa a ser chamado de “Quatro-olhos”. Ao receber alta, incapaz de encontrar seus originais, descobre o que deveria fazer: escrever outra vez o livro.

Esses fatos, contudo, encontram-se dispersos na densa e complexa trama que compõe o romance de Pompeu, pautado por uma imbricada relação com o tempo. Ainda que se espere grande fragmentação e descontinuidade nas narrativas em que a memória esteja em jogo (como nos mostra o pensamento histórico-filosófico de Walter Benjamin² ${ }^{2}$ ), o desencontro com o tempo em Quatro-olhos parece ganhar outras proporções: há indícios de que o texto forme um verdadeiro turbilhão temporal em que o livro perdido, o livro que se escreve e o narrador são tragados.

A fim de evidenciar esse turbilhão, basta atentar para a divisão da narrativa que o romance propõe: na primeira parte, somos apresentados a um homem, recém-saído de uma instituição psiquiátrica, imerso na busca dos originais de um livro que escrevera por mais de

\footnotetext{
${ }^{1}$ POMPEU. Quatro-olhos, p. 15.

${ }^{2}$ Cf. BENJAMIN. O narrador; BENJAMIN. Experiência e pobreza.
} 
10 anos. O processo de busca, em certa medida, corresponde a uma reescrita do livro. Na segunda parte, acompanhamos o cotidiano de sua estadia no hospício e de seus momentos de isolamento, sempre entregues à reescrita de um livro misterioso. Na terceira parte, conhecemos a sua libertação da instituição e uma tomada de decisão (que encerra o romance): “escrever outra vez o livro.”

Não se trata, no entanto, de uma mera inversão da narrativa "internação-libertaçãobusca” em “busca-internação-libertação”. Trata-se, ao contrário, da reunião de momentos díspares e de passados diversos em torno de uma única constante: a reescritura do livro perdido. É necessário observar que, dentro ou fora da instituição psiquiátrica, antes ou depois de tomar sua decisão, Quatro-olhos está sempre a reescrever seu livro. Reescreve-o mesmo antes de pensar em reescrevê-lo. O processo de escrever, “desescrever” e reescrever opera como se estivesse, de fato, voltado para fora do tempo. Sempre na iminência de acontecer e jamais acabada, a escrita de Quatro-olhos se dá em ciclos que jamais encontram seu fim.

\section{ESCREVER PARA TORNAR-SE O HOMEM, TORNAR-SE O HOMEM PARA ESCREVER}

Esse caráter cíclico e infindável do romance de Renato Pompeu nos remete, inexoravelmente, a um grande arquiteto dos labirintos, paradoxos e descaminhos literários: Jorge Luis Borges. Afeito à ideia do infinito como o elemento constituinte da questão literária, Borges se coloca diante do infindável das mais diversas maneiras em seus contos, ensaios e poemas. Em alguns, a questão se circunscreve no nível temático, como na narrativa da biblioteca total em “A biblioteca de Babel”. Em outros, a noção recai sobre o fazer literário, como em “O aleph”. No entanto, há momentos em que o infinito e seus paradoxos operam como obstáculos - ou ainda potencializadores - da escrita, como no conto "A busca de Averróis”.

Como nos revela seu próprio narrador, o conto surge da motivação de contar o processo de uma derrota: “mais poético é o caso de um homem que se propõe um fim que não está vedado a outros, mas sim a ele.”3 Trata-se do desafio que se colocou diante de Averróis, filósofo andaluz de ascendência árabe, ao trabalhar em seu importante comentário sobre a obra de Aristóteles. Oriundo de uma cultura não familiarizada com o teatro, o filósofo se depara com duas misteriosas palavras no texto da Poética: “tragédia” e “comédia”. A narrativa segue o cotidiano e o pensamento do filósofo em sua busca por compreender o que aquelas palavras, visivelmente fundamentais ao texto aristotélico, poderiam significar. Após

\footnotetext{
${ }^{3}$ BORGES. A busca de Averróis, p. 78.
} 
um diálogo com um viajante e um alcoranista, Averróis chega a uma conclusão equivocada sobre o sentido dos estranhos termos. No entanto, a narrativa se desfaz logo em seguida:

Sei que desapareceu bruscamente, como se o fulminasse um fogo sem luz, e que com ele desapareceram a casa e o invisível repuxo e os livros e os manuscritos e as pombas e as muitas escravas de cabelos negros e a trêmula escrava de cabelos ruivos e Farach e Abulcásim e os roseirais e talvez o Guadalquivir. ${ }^{4}$

A razão pela qual a narrativa se dissolve nos é dada por Borges em post-scriptum: a derrota narrada não seria somente de Averróis, mas do próprio Borges. Afinal, de que forma o escritor poderia narrar o filósofo andaluz se dele não tinha mais que alguns esboços? "Senti que a obra zombava de mim”, afirma Borges. E encerra:

Senti, na última página, que minha narrativa era um símbolo do homem que eu fui enquanto escrevia, e que, para escrever essa narrativa, fui obrigado a ser aquele homem e que, para ser aquele homem, tive de escrever essa narrativa, e assim até o infinito. ${ }^{5}$

Para narrar a derrota do filósofo, há que se tornar um escritor igualmente derrotado. Nesse ponto, aquele Borges que tenta compreender o filósofo se torna Averróis em sua busca por desvendar as misteriosas palavras. A escrita só se dá com essa condição. No entanto, a condição só surge a partir da escrita: escrever para tornar-se o homem, tornar-se o homem para escrever. Com esse paradoxo, a narrativa borgeana nos mostra que o texto não pode se livrar da aporia - de fato, ele é a própria aporia. E, somente por conta dela, a escrita acontece, levada ao infinito.

\section{NOS DESERTOS, A ERRÂNCIA}

As menções ao infinito, de fato, não se restringem ao desfecho do conto de Borges. A própria linguagem é vista por Averróis (ou Borges, na amálgama narrador-personagem) como sem-fim. Logo antes de anunciar sua (equivocada) descoberta dos significados dos termos empregados por Aristóteles, Averróis "falou dos primeiros poetas, daqueles que no Tempo da Ignorância, antes do Islã, já disseram todas as coisas, na infinita linguagem dos desertos”. ${ }^{6} \mathrm{O}$ motivo dos desertos, recorrente na literatura borgeana, aparece aqui mais uma vez. A recorrência não se restringe a um nível temático: em Borges, as misteriosas e infindáveis

\footnotetext{
${ }^{4}$ BORGES. A busca de Averróis p. 78.

${ }^{5}$ BORGES. A busca de Averróis p. 78.

${ }^{6}$ BORGES. A busca de Averróis p. 77.
} 
distâncias a serem percorridas nos desertos recaem sobre o homem e a escrita, como afirma o pensador Maurice Blanchot:

Para o homem medido e comedido, o quarto, o deserto e o mundo são lugares estritamente determinados. Para o homem desértico e labiríntico, destinado à errância de uma marcha necessariamente um pouco mais longa que sua vida, o mesmo espaço será verdadeiramente infinito, mesmo que ele saiba que isso não é verdade, e ainda mais se ele o sabe. ${ }^{7}$

Desértico não é apenas o lugar. Desértico é o próprio homem, errante por natureza, sempre destinado a caminhos maiores que sua própria vida. Caminhos como o de compreender termos misteriosos de uma arte estranha - ou como o de narrar um filósofo de que os livros pouco dão notícia. Se, nos desertos de Borges, as distâncias são sempre mais longas que o tempo para percorrê-las, gera-se, nesse “a mais”, o infinito.

Nesses desertos, portanto, pode até haver um ponto de chegada - embora ele sempre esteja mais além. Caminhar rumo a esse ponto de chegada significa jamais se deter. A caminhada com rumo certo, nesse sentido, transforma-se em errância. O homem desértico é protagonista de uma errância sem-fim.

Retomando o romance Quatro-olhos com esse olhar, reconhecemos de imediato o deserto na narrativa. Embora ele de forma alguma surja como imagem no texto de Renato Pompeu, é possível destacar no próprio protagonista essa qualidade desértica. Trata-se de um homem que também se propõe um fim que, a ele, está vedado: encontrar o livro confiscado pelos militares. "Para o médico, por exemplo, sua busca do livro era inútil e sem cabimento, já que o livro deveria estar perdido em algum porão policial, se é que não tinha sido queimado, uma vez que não poderia servir de prova nenhuma”, relembra o narrador. ${ }^{8}$ No entanto, Quatro-olhos realiza infindáveis deambulações pela cidade em busca de seus originais. "Dava medo. Tinha de andar ainda muito e meus olhos se cansavam de tanto ver coisas." "Em meio à empreitada, me detinha por vezes em esquinas e as sombras das nuvens me ultrapassavam, de modo que eu ficava às vezes sombrio e outras iluminado.”" “À noite eu saía para andar e me sentia embrulhado pelas luzes no escuro, o ar mortiço em volta piscando brilhos, ar embaçado escorregando pelos meus músculos, luzes viscosas como óleo

\footnotetext{
${ }^{7}$ BLANCHOT. O livro por vir, p. 137.

${ }^{8}$ POMPEU. Quatro-olhos, p. 186.

${ }^{9}$ POMPEU. Quatro-olhos, p. 29.

${ }^{10}$ POMPEU. Quatro-olhos, p. 31.
} 
nos olhos.”11. Entre alarmes falsos e longas caminhadas despropositadas, a primazia da errância.

Essa deambulação pela cidade, atravessada pela busca da escrita ausente, não é a única forma de errância a que se entrega a personagem. Ao longo da narrativa, a errância de Quatroolhos também se dá no âmbito da memória, entre suas lembranças e olvidos. Embora haja, em alguns pontos da narrativa, um esforço deliberado do protagonista por se lembrar de seu livro perdido e esquecido, a prosa de Pompeu é também repleta de momentos entregues ao esquecimento - seja isso motivo de sofrimento ou complacência. Há, ainda, momentos ambíguos, em que o tempo é dissolvido pelas forças do esquecimento e reorganizado por uma suposta memória do narrador. Como na hora do lusco-fusco, em que luz e treva, dia e noite se tornam um só motivo:

A hora mais adequada para lembrar de tudo é como agora, no fim da tarde,
nem dia nem noite, as cores mudam, passam sombras, nuvens de Santa
Maria, como quando a memória imediata é vencida pela retentiva e a gente,
num lugar desconhecido, se lembra de já ter ali estado - na verdade, a gente
realmente sempre já esteve nos lugares em que nunca foi antes, pois percebe
sempre depois. Já ouvi o que nunca me disseram, apenas demoro a me dar
conta disso.

Não se trata, dessa forma, de uma série de estratégias de memória empregadas pelo narrador - e protagonista - para imprimir suas lembranças no texto. Trata-se, ao contrário, de uma errância da personagem entre memória e esquecimento, por vezes totalmente entregue aos acasos e contratempos do caminho - sua linguagem. Na amplidão desolada do deserto, cumpre errar por um caminho sempre maior que as condições para percorrê-lo. Averróis procura desvendar duas palavras, para ele, indecifráveis. Borges busca recompor um filósofo a partir de traços demasiadamente insuficientes. Quatro-olhos procura encontrar um livro para sempre desaparecido - seja nos porões da cidade ou no deserto de seu próprio esquecimento: “mas me dói o olvidar e a água me molha só por fora, enquanto por dentro fico seco.”13.

\section{O ORIGINAL E A CÓPIA}

Na história de derrota em “A busca de Averróis”, antes de chegar a qualquer conclusão sobre o significado das duas estranhas palavras, o filósofo interrompe a escrita do comentário

\footnotetext{
${ }^{11}$ POMPEU. Quatro-olhos, p. 63.

${ }^{12}$ POMPEU. Quatro-olhos, p. 24.

${ }^{13}$ POMPEU. Quatro-olhos, p. 52.
} 
a Aristóteles ao cair da noite. Em seguida, dirige-se à casa de um conhecido para jantar e, encontrando ali um viajante chegado da China, inicia um longo diálogo com ambos. Falam de amenidades, política e de rosas. Perguntado sobre uma suposta rosa perpétua de um vermelho cor de carne que existiria nas terras que visitara, Abulcásim diz ser essa uma rosa oculta. E acrescenta que "com o Senhor estão as chaves das rosas ocultas e que não existe na terra uma coisa verde ou uma coisa murcha que não esteja registrada em Seu Livro” ${ }^{14}$ No pensamento islâmico, habilmente proferido pela personagem viajante e não por acaso acolhido por Borges em seu conto, Deus criou o mundo segundo uma criação anterior: a de um livro total, em que tudo e todas as coisas estariam escritas. ${ }^{15}$

Uma ideia visivelmente cara a Borges, que a leva às últimas consequências em sua literatura. No ensaio "Del culto de los libros”, o escritor argentino parte da até hoje estrondosa declaração de Mallarmé - “o mundo existe para chegar a um livro” - para se debruçar sobre as aproximações entre livro e mundo, escrita e criação, leitura e História. Passa pelo pensamento grego, o mito de criação islâmico, o Sefer Yetsirah judaico e chega ao pensamento cristão. Por fim, a evocar León Bloy, conclui: “o mundo, segundo Mallarmé, existe para um livro: segundo Bloy, somos versículos ou palavras ou letras de um livro mágico, e esse livro incessante é a única coisa que há no mundo: é, melhor dizendo, o mundo." ${ }^{16}$ Nesse sentido, Borges herda dessa linhagem o pensamento de que o livro não é um mundo possível, segundo a concepção mais comum de ficção. É o mundo. O mundo, por sua vez, é o livro. É fundamental relembrar, aqui, o livro de areia borgeano, livro total e infinito em que todas as coisas estão escritas. Ou teria o próprio livro escrito todas as coisas? ${ }^{17}$

Em certa medida, Renato Pompeu parece incorporar a ideia do livro total na narrativa de Quatro-olhos. No denso híbrido de memórias, divagações, buscas e errâncias que compõem o texto do romance, a noção do livro perdido que vai, aos poucos, sendo composta pelo narrador e protagonista, parece extrapolar os limites do objeto. A princípio, um livro composto de detalhes: "houve capítulo sobre ombros."18 Fragmentos da cidade: "Musgo entre

\footnotetext{
${ }^{14}$ BORGES. A busca de Averróis, p. 73.

${ }^{15}$ Destacamos, aqui, um trecho da epígrafe a Bartleby, ou da contingência, de Giorgio Agamben, retirada do Livro da Escada de Maomé: "Deus criou uma pena de luz para escrever, tão larga e longa que um homem a poderia percorrer, em largura ou comprimento, quinhentos anos. E, esta criada, Deus ordenou-lhe que escrevesse. Disse a pena 'Que escrevo?' A ela respondeu, 'Escreverás a minha sabedoria e todas as minhas criaturas, desde o princípio do mundo até ao seu fim”’.

${ }^{16}$ BORGES. Del culto de los libros, p. 94, tradução nossa.

${ }^{17}$ Cf. BORGES. O livro de areia.

${ }^{18}$ POMPEU. Quatro-olhos, p. 56.
} 
pedregulhos, trilhos de bonde entre pedras, torres sonoras de igrejas sob nuvens rosadas povoavam as folhas brancas marcadas de minhas intenções.”19 Um emaranhado de sons e texturas: "Metálicas manias pululavam, chafurdando-se o adormecido em timbres rumorosos, o oco sonoro a tilintar no escrito. Era o livro. ${ }^{20}$ Uma pletora de formas e estilos literários: “o livro começou como uma coleção de historietas, (...) transmutou-se depois numa avantesma fulgurante sob o influxo avassalador do realismo fantástico e já estava inaugurando uma cascateante nova corrente da literatura quando o perdi." ${ }^{21}$ Um paradoxal compêndio de todos os homens: "Meu livro identificava todas as impressões digitais e a poeira, distinta em cada caso, dentro da unha de cada um. Nele não havia, portanto, nomes.”22 Por fim, a angustiada conclusão: “a única realidade era o livro.”23

Essa ideia da indistinção entre mundo e livro, tão pungente na literatura borgeana e presente, embora de forma mais tímida, na obra de Renato Pompeu, não permite que mundo ou livro passem incólumes. Mais uma vez recorremos à leitura de Blanchot: “se o mundo é um livro, todo livro é o mundo e, dessa inocente tautologia, resultam temíveis consequências.” Uma delas, segundo o pensador, é a perda de um ponto de referência. Se mundo e livro são tudo o que temos, e ambos remetem um ao outro, “eterna e infinitamente”, nada mais encontraremos que "esse poder infinito de espelhamento, essa multiplicação cintilante e ilimitada - que é o labirinto da luz”. Como ressalta o próprio Blanchot, não é pouca coisa. ${ }^{24}$

Também, no momento em que mundo e livro se tocam em um movimento de indistinção em que um duplica o outro, já não é possível saber qual deu origem a qual. Blanchot encontra, aí, o ponto central de "Pierre Menard, autor del Quijote". ${ }^{25}$ Quando o escritor criado por Borges se propõe a escrever dois capítulos de Dom Quixote em indistinção completa da obra de Cervantes, original e cópia se tornam o mesmo. De acordo com Blanchot, “ali onde há um duplo perfeito, o original é apagado, e até mesmo a origem. Assim,

\footnotetext{
${ }^{19}$ POMPEU. Quatro-olhos, p. 86.

${ }^{20}$ POMPEU. Quatro-olhos, p. 95.

${ }^{21}$ POMPEU. Quatro-olhos, p. 44.

${ }^{22}$ POMPEU. Quatro-olhos, p. 17.

${ }^{23}$ POMPEU. Quatro-olhos, p. 62.

${ }^{24}$ BLANCHOT. O livro por vir, p. 138.

${ }^{25}$ BORGES. Pierre Menard, autor del Quijote.
} 
se o mundo pudesse ser exatamente traduzido e duplicado num livro, perderia todo começo e todo fim." 26

Encontramos, aí, dois níveis de profundidade na relação livro-mundo em Quatroolhos. No primeiro nível, a ideia de um livro perdido que, ao menos em memória, fora total, tornando-se todas as coisas, como já ressaltamos. No entanto, em um segundo nível de profundidade, a última sentença do romance - "escrever outra vez o livro”, a decisão final do protagonista - propõe, como única solução para acabar a narrativa, a cópia. Aproximam-se, nesse instante, o livro perdido pela personagem e o livro escrito que o leitor tem em mãos. O original, já perdido e esquecido a priori, pode, nesse momento, apagar-se por ter um possível duplo perfeito. Gera-se, assim, um campo de indistinção entre livro perdido, realidade narrativa e livro escrito. Campo cuja lógica é evocada pelo Averróis do conto de Borges: “infinitas coisas existem na terra; qualquer uma pode comparar-se a qualquer outra”. 27

\section{SEM SAÍDA: O INFINITO}

Quando original e cópia se tornam duplos dispostos em um campo de indistinção, perde-se a origem. Quando livro e mundo se tornam indistintos em Borges, ambos se refletem em um espelhamento contínuo e infinito. Quando livro perdido e livro escrito se tornam possíveis indistintos, em Pompeu, um livro recai sobre o outro, em um movimento segundo o qual a narrativa escreve a própria narrativa infinitamente. Como as tão difundidas Drawing hands de M. C. Escher, a mão que desenha a mão que desenha, mas em uma apropriação literária: o livro escreve o livro que escreve.

Como nos lembrou Blanchot, o mundo duplicado num livro "perderia todo começo e todo fim”. Entre a inexistência de um começo e de um fim, só uma coisa resta: a vastidão infinita da duração. Isso não significa, necessariamente, que o campo espelhado formado por livro e mundo, ou ainda, por livro e livro, não tenha fim. É possível que encontremos, aqui, outra modalidade de infinito: aquele que está contido, aquele que encontra limites, mas do qual não se pode sair. Livro e mundo podem encontrar seus limites. Mas, irremediavelmente e continuamente espelhados um no outro, tornam-se sem saída.

Como o vasto deserto de dimensões bíblicas, que requer mais do que uma vida para que se saia dele, nada mais permitindo que a errância. Ou como a “A biblioteca de Babel” de

\footnotetext{
${ }^{26}$ BLANCHOT. O livro por vir, p. 140.

${ }^{27}$ BORGES. A busca de Averróis, p. 76.
} 
Borges, que tem um número exato de câmaras e uma dimensão tão vasta quanto limitada, embora não se tenha qualquer notícia de uma porta de saída. ${ }^{28}$

“Todo lugar absolutamente sem saída se torna infinito” - Blanchot é categórico. Nesse sentido, infinito é o espelhamento entre livro e mundo na literatura borgeana, em que somos felizmente fadados a errar por esse mundo de letras e esse livro de coisas que é a própria existência. Infinita é a paradoxal exigência da escrita em “A busca de Averróis”, em que é necessário escrever para ser o homem, mas ser o homem para escrever. Infinita é a escrita de Quatro-olhos, cuja única consequência é a decisão por “escrever outra vez o livro”. O conto e o romance, nesse sentido, operam segundo uma lógica em que “antes de ter começado, tudo já recomeça; antes de ter realizado, repetimos"; uma "espécie de absurdo que consiste em voltar sem nunca ter partido, ou em começar para recomeçar”. ${ }^{29}$

Talvez, por essa razão, uma feliz escolha editorial ou um irônico erro de impressão tenha suprimido, na primeira edição de Quatro-olhos, o ponto final após “escrever outra vez o livro”, última sentença do romance. Intenção ou acaso, a ausência de um ponto final nos remete a uma só ideia: a de uma escrita sem saída.

\begin{abstract}
The purpose of this paper is to analyze the notion of infinite in the novel Quatro-olhos, by Renato Pompeu, and its significance to the discussion of act of writing. This reading will be illuminated by Borges's short story "La busca de Averroes” as well as by the writings of Maurice Blanchot.
\end{abstract}

\title{
KEYWORDS
}

Loss, writings of absence, infinite writing

\section{REFERÊNCIAS}

AGAMBEN, Giorgio. Bartleby, escrita da potência. Lisboa: Assírio \& Alvim, 2008.

BENJAMIN, Walter O narrador. In:___. Magia e técnica, arte e política. Trad. Sergio Paulo Rouanet. São Paulo: Brasiliense, 1994a. p. 197-221.

BENJAMIN, Walter. Experiência e pobreza. In: . Magia e técnica, arte e política. Trad.

\footnotetext{
${ }^{28}$ BORGES. La biblioteca de Babel.

${ }^{29}$ BLANCHOT. O livro por vir, p. 137.
} 
Sergio Paulo Rouanet. São Paulo: Brasiliense, 1994b. p. 114-119.

BLANCHOT, Maurice. O livro por vir. Trad. Leyla Perrone-Moisés. São Paulo: Martins Fontes, 2005.

BORGES, Jorge Luis. A busca de Averróis. In: . O aleph. Trad. Flávio José Cardozo. Porto Alegre: Globo, 1972. p. 71-78.

BORGES, Jorge Luis. Del culto de los libros. In: . Obras completas. Barcelona: Emecé Editores, 1989. v. II. p. 93-96.

BORGES, Jorge Luis. O livro de areia. In: . O livro de areia. São Paulo: Companhia das Letras, 2009. p. 100-105.

BORGES, Jorge Luis. Pierre Menard, autor del Quijote. In: Obras completas. Barcelona: Emecé Editores, 1989. v. I. p. 444-450.

BORGES, Jorge Luis. La biblioteca de Babel. Obras completas. Barcelona: Emecé Editores, 1989. v. I. p. 465-476.

POMPEU, Renato. Quatro-olhos. São Paulo: Alfa-Omega, 1976. 